\title{
Hospício Cultural: construindo pontes entre teoria e prática no campo da comunicação
}

Cultural Asylum: constructing bRIDGes betweEn theOry AND PRACTICE IN THE FIELD OF COMMUNICATION 1

\section{Telma Johnson}

Doutora em Comunicação e Sociabilidade Contemporânea pela Universidade Federal de Minas Gerais (UFMG) - Belo Horizonte (MG), Brasil. Mestre em Jornalismo Digital pela Southern Illinois University (SIU) - Illinois, United States. Professora Adjunta da Faculdade de Comunicação da Universidade Federal de Juiz de Fora (UFJF) - Juiz de Fora (MG), Brasil. E-mail: tjohnson@globo.com

Recebido em 29 de outubro de 2013. Aprovado em 14 de fevereiro de 2014

\section{Resumo}

Este artigo visa ampliar o debate sobre a mudança paradigmática de práticas pedagógicas diante das novas diretrizes curriculares que conferem autonomia às habilitações profissionais no campo da Comunicação. As estratégias e os resultados do projeto de investigação multifacetário "Hospício Cultural", baseado na perspectiva do interacionista simbólico Erving Goffman, são analisados como um caminho promissor para a articulação entre teoria e prática em cursos de graduação nas áreas da Comunicação. Esta experiência, baseada na triangulação de métodos qualitativos, revelou os motivos da aversão de alunos às disciplinas teóricas.

Palavras-chave: comunicação; interacionismo; práticas pedagógicas.

\section{Abstract}

This article seeks to broaden the debate about the paradigm shift in teaching practices given the new curriculum guidelines that provide independence to professional enablement in the field of Communication. Strategies and outcomes of the multifaceted research project "Cultural Asylum", based on the perspective of the symbolic interactionist Erving Goffman, are analyzed as a promising avenue for the articulation between theory and practice in undergraduate courses in the areas of communication. This experience, based on the triangulation of qualitative methods, revealed students' reasons for their aversion to theoretical subjects.

Keywords: communication; interactionism; teaching practices. 


\section{Introdução}

Com a publicação das resoluções $n^{\circ} 1$ e $n^{0}$ 2/2013 do Conselho Nacional de Educação (CNE) no Diário Oficial da União de $1^{\circ}$ de outubro de 2013, o campo de estudos da Comunicação entrou, efetivamente, em pleno processo de reconstrução no país. As novas diretrizes curriculares nacionais para os cursos de graduação em Jornalismo e Relações Públicas, instituídas pelas duas resoluções, respectivamente, aceleram o processo iniciado em 2006 com o curso de Cinema e Audiovisual e sinalizam a extensão das mudanças para os demais cursos da área, como Publicidade e Propaganda, Rádio, TV e Internet.

Essas reconfigurações estruturais vêm no rastro das rápidas inovações nas tecnologias da informação e comunicação que têm possibilitado, por um lado, o surgimento de novas formas midiáticas criadas pelo cidadão comum e movidas sob a égide da participação e exigido, por outro, o reposicionamento dos meios tradicionais de comunicação de massa. Nesse cenário contemporâneo, ${ }^{1}$ a emergência de campos autônomos de conhecimento até agora abrigados dentro da grande área da Comunicação reflete a crescente complexidade dos fenômenos comunicacionais e o reconhecimento de que precisam ser estudados dentro de suas especificidades, processos e práticas situacionais.

Os princípios estabelecidos para a reestruturação das matrizes curriculares colocam em evidência a necessidade de ruptura com o velho modelo de ensino-aprendizagem, baseado no adestramento de alunos, para dar lugar à produção coletiva de conhecimento. Isso significa praticar a sala de aula como espaço ${ }^{2}$ de interação social, de trocas de experiências, de construção de significado e de desenvolvimento de espírito crítico. A proposta não é nova, pois já vem sendo contemplada em matrizes curriculares em vários campos de conhecimento. ${ }^{3}$ A novidade está em colocar na ordem do dia, nos novos projetos pedagógicos em construção, os desafios de criar modos de integração entre teoria e prática, privilegiando a interdisciplinaridade e a reflexividade.

Nesse contexto, este artigo apresenta os resultados do projeto multifacetário de investigação "Hospício Cultural" que coordenei e desenvolvi, em 2012, a partir da

1 O termo "contemporâneo" é aplicado aqui no sentido utilizado por Giorgio Agamben (2009) ao se referir a uma ideia de temporalidade em que passado, presente e futuro não são instâncias separadas, estanques, mas intimamente entrecruzadas e referenciadas. O presente, nesse sentido, carrega a força de um passado e, simultaneamente, antecipa um futuro.

2 A noção de "espaço" que empregamos aqui é a proposta por Michel de Certeau (2004) ao delimitar os termos "espaços" e "lugares". A definição de lugar implica estabilidade, demarcação. Espaço, ao contrário, remete ao sentido de movimento, de ações em construções, em devir. "Espaço é um lugar praticado" (CERTEAU, 2004, p. 202).

3 Uma sistematização do construtivismo como produção de conhecimento em aula pode ser encontrada nas obras de Vasco P. Moretto $(2009,2011$ e 2012).

$108 \frac{\text { Comunicação \& Inovação, PPGCOM/USCS }}{\text { v. 15, n. } 29 \text { (107-122) jul-dez } 2014}$ 
constatação de que boa parcela dos alunos de graduação em Comunicação tem aversão às disciplinas teóricas (Bonin, 2005; GoMes, 2006; Johnson, 2010b). O incômodo de que os alunos geralmente acreditam que a teoria antecede a prática, é desconectada do mundo real e, portanto, é baseada em abstrações, me levou a formular a seguinte pergunta de pesquisa: como reduzir a resistência dos alunos de Comunicação Social em relação às disciplinas teóricas da grade curricular da graduação?

O termo "resistência" foi operacionalizado como aversão às aulas. A "Comunicação Social" foi enquadrada como o curso da área das Ciências Sociais Aplicadas e suas habilitações, de acordo com a classificação do Ministério da Educação em vigência em 2012. As "disciplinas teóricas" foram definidas como disciplinas que trabalham com noções e conceitos tentativos de explicar uma dada realidade praticada em contexto. As disciplinas "Teoria da Comunicação" e "Fundamentos das Ciências Sociais" foram adotadas, neste estudo, por serem lecionadas em períodos iniciais da graduação, tanto em instituições públicas como privadas. Embora às vezes recebam nomes diferentes e se desdobrem em mais de uma disciplina, com cargas horárias cumulativas, as ementas são aproximativas.

Esse desenho conduziu à escolha do estudo de caso como método, pela possibilidade de explorar e explicar o fenômeno usando a triangulação de técnicas qualitativas. ${ }^{4}$ A perspectiva do interacionista simbólico Erving Goffman, da Escola de Chicago (EUA), foi tomada como base para o desenvolvimento da narrativa ficcional do curta-metragem intitulado "Hospício Cultural". O roteiro que criei, baseado na obra Asylums: Essays on the social situation of mental patients and other inmates ${ }^{5}$ (GoFFMAN, 1961), foi discutido e encenado por alunos da Comunicação participantes do projeto. Após a postagem do vídeo no YouTube, a técnica de grupo focal foi aplicada para a avaliação do processo de ensino e aprendizagem.

O objetivo geral foi dar voz aos alunos para identificar o grau de resistência às disciplinas teóricas e compreender as origens do problema, como exercício de reflexão sobre possíveis modelos e práticas pedagógicas capazes de estimular os alunos no processo de produção de conhecimento superando a dicotomia teoria-prática.

\section{legado de Goffman para os estudos comunicacionais}

O Interacionismo Simbólico ficou obscurecido, por muitas décadas, não apenas pela força do pensamento positivo-funcionalista no mundo ocidental, mas também

4 O termo "triangulação" não implica o uso de três técnicas de pesquisa, mas uma combinação de várias técnicas que podem revelar as múltiplas facetas de um fenômeno (Johnson, 2010).

5 "Manicômios, prisões e conventos" na tradução para a língua portuguesa, publicada em 1974, pela editora Perspectiva (SP). 
marxista, na América Latina. O cenário midiático contemporâneo, com as novas tecnologias da informação e comunicação, tem nos mostrado que perspectivas essencialistas não dão conta da apreensão e compreensão desses novos fenômenos na vida social. O resgate da dimensão interpretativa, interacionista surge, então, como um caminho intermediário promissor nos estudos das práticas sociais e fenômenos comunicacionais.

O legado da obra goffmaniana, focada na "administração de impressões" (looking good), como práticas sociais cotidianas adotadas nos mais diferentes ambientes e situações do mundo real, nos pareceu pertinente para sensibilizar alunos acerca de formulações teóricas resultantes de observações empíricas sobre o mundo cotidiano na área da comunicação. Na perspectiva do Interacionismo Simbólico da Escola de Chicago, Goffman aborda os rituais das interações sociais, os processos de interpretação individuais e a construção coletiva de significados.

Após 30 anos de sua morte, completados em 2012, o pensamento de Goffman sobre a vida cotidiana como teatro não envelheceu, ao contrário. Embora nascido no Canadá, Goffman desenvolveu suas pesquisas microssociológicas na Escola de Chicago (EUA), focando na capacidade humana da autoreflexividade, em um estilo tão ou mais atraente do que o "pai" do Interacionismo Simbólico, George Mead, ou mesmo sobre a etnografia urbana aplicada aos estudos das interações desenvolvida por Herbert Blumer, como tratei com detalhes em outros trabalhos (Johnson, 2010a; 2010b).

Em termos pragmáticos, a obra Asylums baseou o processo criativo de roteirização bem como a construção ficcional do curta-metragem que intitulei "Hospício Cultural". Em breves palavras, Goffman mostra, com profundidade, a vida de doentes mentais em processos de reconstrução dos seus "eus", ou seja, reorganizando suas identidades subjetivas em instituições psiquiátricas. Tomei como pressuposto que a temática da loucura é universal e todos nós temos algum tipo de familiaridade com o assunto como experiência social e psicológica. É um problema silenciado, mas não historicamente desconhecido.

Foucault (1978) explorou, com propriedade, os diferentes sentidos da loucura ao longo dos tempos.

Se a loucura do século XII está como que dessacralizada é de início porque a miséria sofreu essa espécie de degradação que a faz ser encarada agora apenas no horizonte da moral. A loucura só terá hospitalidade doravante entre os muros do hospital, ao lado de todos os pobres. É lá que a encontramos ainda até o final do século XVIII. Com respeito a ela, nasceu uma nova sensibilidade: não mais religiosa, porém moral. Se o louco aparecia de modo familiar na paisagem humana da Idade Média, era que como vindo de um outro mundo. Agora, ele vai destacar-se sobre um

$110 \frac{\text { Comunicação \& Inovação, PPGCOM/USCS }}{\text { v. 15, n. } 29 \text { (107-122) jul-dez } 2014}$ 
Hospício Cultural: construindo pontes entre teoria e prática no campo da comunicação

fundo formado por um problema de "polícia", referente à ordem dos indivíduos na sociedade. Outrora ele era acolhido, porque vinha de outro lugar; agora, será excluído porque vem daqui mesmo, e porque seu lugar é entre os pobres, os miseráveis, os vagabundos. A hospitalidade que o acolhe se tornará, num novo equívoco, a medida de saneamento que o põe fora do caminho. De fato, ele continua a vagar, porém não mais no caminho de uma estranha peregrinação: ele perturba a ordem do espaço social. Despojada dos direitos dos direitos da miséria e de sua glória, a loucura, com a pobreza e a ociosidade, doravante surge, de modo seco, na dialética imanente dos Estados (Foucault, 1978, p. 72).

Nesse sentido, há outro fundamento para a escolha de Asylums na construção do "Hospício Cultural". Ao romper com uma tradição de pesquisas baseadas em relatos médicos, Goffman inaugurou uma linha de investigação voltada para a apreensão e compreensão das interações sociais no interior de uma instituição para doentes mentais sob um olhar socioetnográfico, em vez de psiquiátrico. A problematização da realidade em instituições psiquiátricas nos serviu como fonte analítica para uma reconstrução ficcional sobre a utilização de táticas e estratégias conscientes dos internos como práticas de sobrevivências do "eu".

Goffman coletou fortes evidências de que mesmo em uma "instituição total" psiquiátrica não apenas médicos, enfermeiros, atendentes e corpo diretivo, mas, também, os internos assumem papéis e vestem máscaras, como táticas de ajustamentos sociais, para evitar constrangimentos, castigos e até usufruir de benefícios e privilégios. Uma "instituição total" é qualquer lugar onde as pessoas levam uma vida fechada, intramuros, longe da sociedade, formalmente administrada (GofFman, 1974/1961, p. 11), como asilos, hospitais para doentes mentais, leprosários, penitenciárias, campos de concentração, navios, mosteiros, conventos e mesmo determinados tipos de escolas.

\section{Percurso metodológico: roteirização, encenação e grupo focal}

Asylums é uma obra que relata a pesquisa empírica etnográfica de Goffman realizada no hospital psiquiátrico St. Elizabeths, nos Estados Unidos, entre os anos de 1954 e 1957. Na investigação, o sociólogo reuniu evidências que o uso de táticas como administração de impressões era uma prática normal na instituição. O estudo de Goffman centrou nos papéis conscientemente construídos pelos pacientes internos, mostrando empiricamente a persistência e apresentação do "eu" e do empreendimento humano no desenvolvimento e manutenção de uma comunidade sob condições de controle intensivo e sem contato com o mundo exterior. 
A ampla dimensão de Asylums, retratando aspectos psicológicos, sociológicos e comunicacionais no interior de uma instituição psiquiátrica fechada, nos possibilita enquadrar o projeto "Hospício Cultural" sob o olhar da interdisciplinaridade. Goffman relata que os pacientes dentro de uma instituição para doentes mentais passam por processos de reorganização dos seus "eus" (identidades existentes antes de entrarem no ambiente hospitalar) como forma de enfrentar a tensão entre o mundo original e o novo mundo institucional. Cada processo de readaptação, nesse sentido, corresponde a um processo de mutilação do "eu" anterior.

Nesses processos, os pacientes criam diferentes táticas, de forma consciente, tanto para evitar castigos da equipe hospitalar como para serem recompensados com os chamados "sistemas de privilégios" por estarem cooperando com as regras da instituição. Os privilégios são variados e consistem, por exemplo, em ter os melhores serviços, melhores quartos e camas, alguns luxos secundários (café na enfermaria), a possibilidade de sair da enfermaria sem supervisão, ser tratado com respeito e delicadeza pelo pessoal e até antecipar o término do tratamento médico.

\section{O roteiro}

$\mathrm{Na}$ construção da narrativa ficcional do "Hospício Cultural", que vou me referir a partir deste momento como simplesmente $\mathrm{HC}$, assumi a realidade social como um constante devir, nunca dada, mas construída, desconstruída e reconstruída nos dinâmicos processos de interação social (MEAD, 1934; Blumer, 1935, 1936, 1955, 1969, 1980). Os papéis dramatúrgicos estudados por Goffman não foram entendidos como simples "máscaras" colocadas pelos indivíduos em diferentes situações sociais, mas como aspectos reais e autênticos dos seus complexos "eus".

Nessas interações sociais cotidianas, as ações são baseadas em significados construídos no tecido dos vínculos sociais, mas que passam por processos de interpretações subjetivas. Os atores de Goffman estão vivos, em um sentido interpretativo. Eles pensam, assistem, definem e tentam antecipar o outro; eles planejam e representam. Eles cometem erros e se reajustam - tanto individualmente como em cooperação com os outros. Eles experienciam orgulho. Mas, também, sentem vergonha e embaraço - e se policiam, conscientemente, colocando e testando máscaras que os protejam contra dissabores sociais.

$\mathrm{O}$ processo de construção dos personagens principais do $\mathrm{HC}$ utilizou e adaptou a tipologia de Goffman sobre o comportamento individual e social em uma situação de instituição psiquiátrica. Goffman identifica em Asylums, pelo menos, oito personagens de acordo com as suas características pessoais, comportamentos sociais dentro da instituição,

\footnotetext{
$112 \frac{\text { Comunicação \& Inovação, PPGCOM/USCS }}{\text { v. 15, n. } 29 \text { (107-122) jul-dez } 2014}$
} 
táticas e estratégias utilizadas pelos internos e corpo diretivo no dia a dia. O sociólogo também identificou como o corpo diretivo veste "máscaras" quando familiares dos internos os vêm visitar e como os internos mais antigos exploram os recém-chegados tentando impor "regras" por eles mesmos criadas para tirar vantagens e lançar mão de jogos de poder.

Em se tratando de um ambiente psiquiátrico fechado, poderíamos pensar que regras, práticas de dominação e processos de manipulação, comumente vistas em sociedades extramuros, não estariam em organizações muradas. Mas essas elaborações sociais também estão lá, em formas de ajustamentos formais ou informais. Como explica Goffman (1974/1961):Os sociólogos sempre procuraram as maneiras pelas quais um indivíduo é formado por grupos, identifica-se com estes, e afinal se destrói, se não for por eles apoiado emocionalmente. No entanto, quando observamos de perto o que ocorre num papel social, um reduto de interação social, um estabelecimento social - ou qualquer outra unidade social - não vemos apenas a atração exercida pela unidade. Sempre encontramos um indivíduo que emprega métodos para manter certa distância, algum recanto livre entre ele e aquilo com que os outros desejam identificá-lo. Sem dúvida, um hospital público para doentes mentais dá um solo muito rico para o desenvolvimento de tais ajustamentos secundários mas, na verdade, como erva daninha, surge em qualquer tipo de organização social. [...] em todas as situações realmente estudadas, o participante ergue defesas contra sua ligação social [...] (Goffman, 1974, pp. 257-258).

Com base na tipologia de Goffman, como podemos ver no Quadro 1, o roteiro do curta HC foi baseado em oito personagens principais:

Quadrro 1: A construção dos personagens do HC.

\begin{tabular}{cc} 
Tipologia de Goffman & Hospício Cultural \\
1. Tática do afastamento da situação & 1. E.T. (alienação) \\
\hline 2. Tática da intransigência & 2. João Rebelde (“o contra") \\
\hline 3. Tática da colonização & 3. Maria Vaicomas ("o lar") \\
\hline 4. Tática da conversão/1 & 4. Carla Convertida ("a disciplinada") \\
\hline 5. Tática da conversão/2 & 5. Lili Deduro (“dedo-duro") \\
\hline 6. Tática da viração & 6. Fernanda Kaloura ("novata”/choque de culturas) \\
\hline 7. Papéis intra e extramuros & 7. Dr. Ervingman \\
\hline 8. A exibição institucional & 8. Dra. Ignácia \\
\hline
\end{tabular}

Após a construção dos personagens, a narrativa ficcional do HC foi desenvolvida na forma de um curta-metragem no gênero comédia. A história do HC retrata acontecimentos ocorridos na temporalidade de uma semana, iniciada em uma segunda-feira e encerrada na segunda-feira seguinte, no ambiente de um hospital psiquiátrico. No enredo, não existe um protagonista, pela opção que se fez de construção de um roteiro não 
totalmente fechado. Esta estratégia abriu possibilidades para que a criatividade dos alunos envolvidos no projeto aflorasse na encenação dos personagens nos processos de interação.

\section{Encenação}

O audiovisual foi produzido com alunos do curso de Comunicação Social da Universidade Estácio de Sá, Unidade Belo Horizonte, entre os meses de maio e junho de 2012. O processo seletivo foi aberto e divulgado para os alunos de todos os oito períodos do curso, tanto do turno da manhã como da noite. Um total de 32 alunos se inscreveu para o teste de elenco, realizado em duplas, que utilizou um trecho do ato "O mendigo", da peça teatral “Ácido Sulfúrico”, escrita por Durval Cunha. Não foi exigida qualquer experiência dramatúrgica prévia. Os alunos não selecionados foram convidados e aceitaram atuar no elenco de figurantes, mediante o recebimento de 50 horas de Atividade Acadêmica Complementar (AAC).

Os critérios de seleção, em ordem de prioridade, foram: 1) disponibilidade de horários para ensaios e filmagens; 2) interpretação de texto; 3 ) aptidão. No primeiro encontro com o elenco principal, no dia 15 de maio, os alunos assinaram o Contrato de Aprendizagem e Confidencialidade, com cessão de direitos de imagem e compromisso de participação na segunda etapa do projeto que avaliaria, em grupo focal, a experiência pedagógica. Neste mesmo encontro, proferi uma palestra sobre Asylums situando onde a obra se insere no pensamento goffmaniano, seguida de uma sessão de dinâmica de leitura coletiva do roteiro. Após várias leituras, os alunos escolheram personagens com os quais apresentavam maior afinidade e identificação.

O quadro abaixo apresenta os alunos do elenco principal, o período seletivo e o curso em que estavam matriculados à época das gravações do projeto audiovisual e os personagens que representam no HC.

Quadro 2: Alunos e personagens do HC.

\begin{tabular}{cccc} 
Nome & Período & Curso & Personagem \\
Adriana Mateus T. Macedo & $3^{\text {o }}$ & Publicidade & Dra. Ignácia \\
\hline Cleidiane Marques Reis & $1^{\text {o }}$ & Publicidade & E.T. \\
\hline Laura Helena Silva Lima & $7^{\text {o }}$ & Jornalismo & Lili Deduro \\
\hline Luiza Gabriele F. dos Santos & $1^{\text {o }}$ & Jornalismo & Carla Convertida \\
\hline Mateus Dantas Santana & $1^{\text {o }}$ & Jornalismo & Dr. Ervingman \\
\hline Marinalva Santana & $4^{\text {o }}$ & Jornalismo & Maria Vaicomas \\
\hline Samuel Henrique Costa & $7^{\text {o }}$ & Jornalismo & João Rebelde \\
\hline Thalita Cardoso Silva & $7^{\text {o }}$ & Publicidade & Fernanda Kaloura \\
\hline
\end{tabular}

$114 \frac{\text { Comunicação \& Inovação, PPGCOM/USCS }}{\text { v. 15, n. } 29 \text { (107-122) jul-dez } 2014}$ 
$\mathrm{O} \mathrm{HC}$ resultou em um curta-metragem de 17 minutos e 27 segundos e foi compartilhado no YouTube na primeira semana de setembro de $2012 .{ }^{6} \mathrm{O}$ audiovisual foi selecionado e apresentado em outubro de 2012 no $3^{\circ}$ Seminário Histórias de Roteiristas: Múltiplas telas, em São Paulo, promovido pela Universidade Presbiteriana Mackenzie, com o patrocínio do Departament of Film da University of Nevada, Latin America Games for Change, Cidade do Conhecimento-USP, Red Ibero Americana de Narrativas Audiovisuales, entre outras parcerias.

\section{grupo focal}

A técnica de entrevista em grupo focal foi utilizada como forma de avaliação dos resultados da experiência do $\mathrm{HC}$ com os alunos participantes do projeto. A adoção da técnica de entrevista surgiu como uma decisão natural, por permitir privilegiar a interação e a troca de significados entre os alunos com um mínimo de interferência da moderadora. O propósito central foi facilitar debates espontâneos baseados em percepções, opiniões, crenças e atitudes para saber o nível de satisfação da experiência e coletar dados capazes de responder os objetivos do projeto de pesquisa.

O grupo focal foi realizado em 22 de outubro de 2012 com a presença de sete dos oito integrantes do elenco principal (o aluno ausente não conseguiu liberação da empresa onde estagiava à época). Os participantes do grupo focal receberam orientações sobre a dinâmica da atividade e foram encorajados a falar espontaneamente e contribuir para o debate, sem a preocupação de serem identificados posteriormente. Para isso, cada aluno recebeu um número arbitrário com o qual seria identificado depois pela pesquisadora no estágio de análise e interpretação dos dados.

O encontro foi gravado em áudio, para fins de registro de transcrição integral, e teve a duração de três horas. Um roteiro previamente elaborado serviu como fio condutor (Quadro 3) envolvendo três partes: 1) perguntas mais amplas, desestruturadas; 2) perguntas focais, estruturadas; e 3) perguntas genéricas, de fechamento da entrevista focal, concentradas na avaliação crítico-construtiva da prática pedagógica do projeto HC.

No desenvolvimento da técnica de grupo focal, algumas perguntas que seriam feitas pela pesquisadora, no papel de moderadora, foram excluídas porque os alunos, em suas respostas, foram antecipando informações, pontos de vista, impressões, sentimentos e partilhas de opinião no processo de interação com os colegas. Percebeu-se, assim, que “o ambiente natural e holístico" a que se referiu Gaskell (2002, p. 76) se reproduziu no grupo focal do Hospício Cultural. Foi constatado que:

6 O vídeo está no endereço: http://www.youtube.com/watch?v=HvR00241Eb0.

$$
\frac{\text { Comunicação \& Inovação, PPGCOM/USCS }}{\text { v. 15, n. } 29 \text { (107-122) jul-dez } 2014}(115
$$


Quadro 3: Roteiro preliminar do grupo focal.

1. Motivação em participar do projeto audiovisual HC;

Parte 1

2. Experiências diretas ou indiretas com pessoas com transtornos mentais;

3. Construção do personagem;

4. Experiência anterior com dramaturgia.

1. Estudo de teorias em geral - antes de depois do HC;

Parte 2

2. Dificuldades/facilidades com disciplinas teóricas do curso de Comunicação;

3. Percepção do Interacionismo Simbólico (IC) após HC;

4. Em quais outras situações o IC se aplica?

1. Avaliação da experiência;

Parte 3

2. Pontos fortes e fracos da prática pedagógica;

3. Percepção sobre doentes mentais pós-HC;

4. Sugestões de como atrair o interesse dos alunos para disciplinas teóricas.

1) Uma sinergia emergiu da interação social;

2) Foi possível observar o processo do grupo, a dinâmica da atitude e da mudança de opinião e a liderança de opinião;

3) Houve um nível de envolvimento emocional entre os membros do grupo.

\section{Principais achados}

Em linhas gerais, todos os participantes do grupo focal revelaram ter decidido participar do projeto "Hospício Cultural" movidos tanto pela "curiosidade" como por acreditarem que seria uma oportunidade de interagir com outros alunos, revivendo velhas experiências de infância, quando "fazer teatro na escola" era um momento de "brincadeira", "lazer" e "convivência com o outro".

Os alunos relataram que logo no primeiro ensaio, após a seleção do teste de elenco, perceberam a seriedade e o real propósito do projeto: uma releitura da obra de Goffman, sob a perspectiva da problemática sociológica dos doentes mentais, como prática pedagógica voltada para a integração de disciplinas teóricas e práticas da grade curricular do curso de Comunicação Social.

Nesta etapa, os alunos revelaram, indistintamente, ter tido experiências diretas e indiretas com alguém acometido por transtornos mentais. As imagens que os alunos fazem dessas pessoas, em sua maioria, estão relacionadas com confusão mental, instabilidade

$116 \frac{\text { Comunicação \& Inovação, PPGCOM/USCS }}{\text { v. 15, n. } 29 \text { (107-122) jul-dez } 2014}$ 
comportamental, mudanças de humor e obsessões. A preocupação reflexiva em como se relacionar com este "outro", quais atitudes e ações seriam apropriadas, foi revelada nas falas dos entrevistados:

(Participante 5) - Tinha uma tia com problemas mentais que faleceu aos 39 anos. Tenho um primo que tem esquizofrenia. A gente tem que ter todo o cuidado quando ele está em crise (...) Ele sempre acha que eu mexo nas coisas dele...

(Participante 6) - Tenho uma tia esquizofrênica. Ela vive num mundinho só dela, mas ainda tem a percepção de que é preciso estar arrumada o tempo todo. Ela adora ganhar batom de presente e fala dos namorados o tempo todo. Ela não tem nenhum, é tudo imaginário. Ela pegou a mania de dizer que eu escondo as pantufas delas... Em certos momentos ela fica muito agressiva, então aprendi a ter um jogo de cintura. Fico pensando no imaginário dela e começo a brincar que escondi mesmo...

(Participante 3) - Mas tem casos de loucura que temos que prestar atenção no que eles dizem. Há um fundo de verdade na história. A Dra. Vera tinha uma paciente que só falava francês, lembrava de tudo, fatos, tudo. Ela foi uma mulata do Sargentelli [Oswaldo Sargentelli, empresário brasileiro de casas de espetáculos de samba, falecido em 2002], casou com um suíço, sofreu um acidente e perdeu a memória... A médica comprovou que era verdade, ou seja, eles misturam o que aconteceu e o que nunca aconteceu.

(Participante 1) - Tenho um tio que dizem que queimou os neurônios de tanto estudar. A imagem que tenho dele é que ele adorava andar muito bem penteado. Para mim, ele não era nada demais. A única coisa é que ele vivia bebendo, mas era passivo.

(Personagem 4) - Tive alguns contatos com vizinhos - distúrbios, esquizofrenia. O que eu sentia era um misto de pena, dó, agonia, não sabia como reagir. Se eu reagisse com carinho, eles eram agressivos. Se eu brincava, eles também já levavam para um lado agressivo...

Essas experiências, diretas e indiretas, ajudaram os alunos a construir seus personagens em torno de características específicas. Quanto às experiências indiretas, um aluno chegou a citar experiências midiáticas - perfis ou personagens construídos pelos meios de comunicação de massa que afetam, de certa forma, a esfera da recepção. "A construção do meu personagem foi baseada no personagem 'Tonho da Lua', da novela Mulheres de Areia. Ele tinha esses tiques, esquisitices, com a mão que eu resolvi adotar”, revelou a participante 5. A novela brasileira foi transmitida pela extinta TV Tupi, em 1973, com 
remake da TV Globo, em 1993, e reprisada também pela TV Globo em 2011. O personagem Tonho da Lua, vivido pelo ator Marcos Frota, era deficiente e construía esculturas de areia.

Acomposição dos personagens também envolveu, de acordo com os entrevistados, pessoas que, aparentemente, são normais, mas se comportam de formas idiossincráticas de acordo com as situações. A personagem 3, por exemplo, afirmou que se baseou em uma vizinha. "Era tranquila, mansa, mas se chamassem ela de Elza ela atacava, jogava pedra...". Já a personagem 4 revelou: “Ah, lembrei de pessoas no cotidiano da gente que se fazem de sonsas para viver...". O personagem 2 , de forma mais elaborada, disse que tomou por base o conceito de biometria, que envolve formação e deformação: "Há muita gente por aí que luta por tudo, tem vários conceitos, não obedece a padrões sociais e, no fim, elas nem sabem quais são as causas que elas realmente defendem".

O grupo teve a chance de comentar sobre os resultados do HC em termos de compreensão sobre a problemática dos doentes psiquiátricos e a sua própria experiência de vida. É perceptível, nas respostas, uma mudança de atitude dos alunos a partir do próprio balanço que fazem da experiência e da articulação que fizeram entre a teoria e a prática.

(Participante 3) - Eu só estava preocupada comigo, com o meu "eu". Penso em ir a um hospício visitar pessoas e conhecer melhor o mundo deles. Eu nunca liguei para os loucos.

(Participante 5) - O que a gente fez no "Hospício" está diretamente ligado ao que a gente viu na sala de aula. Todo mundo representa algum tipo de papel na sociedade. Cada um mostra alguém que, na verdade, não é. É uma imagem que você vai construindo com medo do seu verdadeiro eu. Puxa... eu gosto disso e se o fulano souber vai me criticar, não quero ser criticado, não quero ficar sozinho.

(Participante 4) - A sociedade, de alguma forma, se impõe, por ser tão crítica, tão preconceituosa, uns são mais exageradamente hipócritas que outros. É um disfarce, mais uma cara. Se a pessoa que assume o que ela, é julgada, socialmente excluída.

(Participante 8) - Eu achei muito interessante porque o que Goffman coloca é que a gente representa o tempo todo. Por exemplo, você é um personagem quando está trabalhando, você é outro quando está estudando, você é outro quando está no convívio com a classe C ou D. O que eu não pensava era que o louco também tem esse sentido. Ele também cria, ele também sabe se comportar de acordo com as regras igual a gente... Será que, num certo sentido, todos nós não somos loucos? Será que ele é realmente louco? Acho que não. Acho que ele é um deslocado da sociedade, só pensa diferente. Talvez ele seja o real...(Participante 4) - Eu não pensava que eles tinham uma sensibilidade aflorada. 
Hospício Cultural: construindo pontes entre teoria e prática no campo da comunicação

(Participante 1) - Eu comecei a olhar para o meu próprio comportamento. Eu me senti na pele das pessoas, tanto que depois das gravações eu ficava "viajando" e pensando: puxa, é muito sério essa coisa. Eu custava a voltar ao normal...

(Participante 2) - Acho que o Goffman conseguiu definir muito bem essas máscaras sociais que são utilizadas pelas pessoas de acordo com o ambiente social na qual elas pertencem... Eu não aprendi nada disso em sala de aula. As coisas são faladas muito superficialmente.

(Participante 8) - Eu não me lembro de ter visto nada do Goffman em sala de aula.

(Participante 6) - Ah, eu me lembro que vi muitas coisas do Goffman, mas não entendi nada naquela época.

Uma questão discutida, que não estava no roteiro inicial, foi provocada pelos próprios alunos/participantes do projeto. Cada um tinha uma história para contar como reuniu família e amigos para ver o curta-metragem que seria exibido no YouTube. Alguns prepararam encontros para celebrar, comes e bebes, enfim. Todos os alunos, ao final, relataram desapontamentos com as reações da família e dos amigos:

(Participante 2) - Muitos criticaram, não entenderam. No final, todo mundo fica: "E aí"? Eu fico muito chateado porque só mostra a ignorância das pessoas em julgar.

(Participante 5) - É natural do ser humano não se arriscar, só criticar. Tipo assim, se der errado não sou eu.

(Participante 8) - Eu já fui logo explicando. Você vai assistir? É isso. Dei logo a orientação da teoria do Goffman. Se eu não explicar, ninguém entende. Tenho que explicar para que as pessoas venham assistir com outros olhos.

(Participante 6) - O problema é o contexto teórico. As pessoas assistem e não entendem, fica chato.

Em relação à questão sobre os estudos de teorias, em geral, e os estudos de teorias no curso de Comunicação, em particular, constantes na Etapa 2 do Quadro 3, algumas respostas foram bastante significativas:

(Participante 6) - É preciso ter uma dinâmica na sala de aula para chamar a atenção dos alunos, para provocar o interesse. Teoria é uma coisa muito cansativa. Vi, lembro que estudei o 
Goffman, mas era cansativo porque o professor ficava só passando slides. Eu e meus colegas ficávamos pensando: e aí? Cadê a explicação?

(Participante 2) - Eu fiz Teorias da Comunicação no Espírito Santo, onde eu morava antes de vir para BH. Na verdade lá, eu não aprendi teorias da comunicação, aprendi teorias da vida da minha professora porque a aula dela era só contar a vida dela. Infelizmente a sala era enorme, muita gente, e ela dava 10 para todo mundo para evitar problemas. Eram provas que a maioria sabia que tinha errado as questões, mas a gente pensava - se tenho $10 \mathrm{vou}$ reclamar de quê?

(Participante 8) - Eu gosto muito de teoria. O problema das aulas é que eu gosto de linkar o que aconteceu com a época em que vivemos. Qual é o pensamento da época para a gente tentar entender porque eles pensavam dessa ou daquela forma. Em muitos casos, o problema é que os alunos faltam e perdem o fio da meada...

(Participante 1) - Eu já tenho um pouco de dificuldade com esse negócio de teorias, mas eu procuro me inteirar... Eu sei que o que está sendo ensinado é importante, mas como? Como pode ser aplicado na vida da gente?

(Participante 2) - Eu acho também que é uma questão de didática. Eu já tive uma professora que vinha com os textos mais macabros do mundo, a gente não entendia bulhufas, mas quando ela explicava eu compreendia.

(Participante 8) - Mas eu acredito que ficou claro no HC que a teoria é a base do que vem acontecendo; sem as teorias, as coisas ficam vazias. A teoria explica: ó, acontece isso por causa disso...

(Participante 2) - Mas eu acho também que os professores subestimam muito a inteligência dos alunos porque a maioria dos textos que a grande maioria dos professores oferece são fáceis, normais para lidar. Mas quando chegam textos mais elaborados, com uma linguagem mais rebuscada a gente reclama, porque não estamos acostumados a lidar com esse tipo de conteúdo, que deveríamos estar...

(Participante 5) - Eu me sentia burra nessas aulas. Não deveria ser assim...

Ao final do grupo focal, os alunos declararam só ter entendido as noções de sociedade e organização social na perspectiva do interacionismo simbólico de Goffman, na prática, após a experiência com o projeto Hospício Cultural. Os alunos, mesmo sem ter sido provocados a falar sobre o cenário midiático contemporâneo movido pelas relações

$120 \frac{\text { Comunicação \& Inovação, PPGCOM/USCS }}{\text { v. 15, n. } 29 \text { (107-122) jul-dez } 2014}$ 
entre novas e velhas mídias, levantaram o assunto. Eles observaram que as pessoas sempre interagiram por meio de máscaras para serem aceitas dentro dos valores e padrões sociais impostos em uma determinação época e lugar, mas agora estão em cena também novas formas de máscaras, intermediadas por computador. Essas múltiplas representações, para os alunos, tornam ainda mais complexa a vida social.

"Em função da queda das barreiras de tempo e espaço, você se sente na obrigação de também se posicionar, elogiar, criticar", disse o participante 6 , como que profetizando a força da mobilização pelas redes sociais da onda de protestos que tomou as ruas e as praças do país em junho de 2013.

\section{Considerações finais}

O estudo indicou que há uma relação direta entre o alto grau de resistência dos alunos às disciplinas teóricas no campo da Comunicação e as práticas pedagógicas que vêm sendo utilizadas pelos docentes em sala de aula. Os alunos têm a concepção de que o ensino da teoria é chato, cansativo, tanto pela falta de dinâmica nas aulas como pela ausência de exemplos que contextualizem a dimensão prática da teoria com o mundo concreto. Há, ainda a percepção de que existe um grande desequilíbrio entre professores e didáticas: eles não apenas criticam o uso exagerado dos slides, mas também reclamam dos textos superficiais que não os preparam para uma leitura crítica. Por isso, sentem-se despreparados e impotentes quando são chamados a trabalhar com textos cuja linguagem e conteúdos são mais aprofundados e rebuscados.

A experiência do Hospício Cultural demonstrou que a articulação entre teoria e prática continua a ser um grande desafio a ser superado para que a sala de aula se transforme realmente em um espaço praticado de interação social, troca de experiências, construção de significado e desenvolvimento do espírito crítico. Em suma, um espaço real de produção coletiva do conhecimento. A percepção dos alunos sobre o interacionismo simbólico na perspectiva goffmaniana, após a atividade prática de discussão do roteiro e encenação do audiovisual HC, demonstra que os obstáculos podem ser vencidos na relação ensino-aprendizagem quando há a compreensão de que teoria não é abstração, mas uma forma científica de atribuir sentido aos fenômenos, cada vez mais complexos, ocorridos sob condições e contextos históricos e sociais situados.

\section{Referências}

Agamben, Giorgio. O que é o contemporâneo? E outros ensaios. Chapecó: Argos, 2009. 
Blumer, Herbert. Social attitudes and non-symbolic interaction. Journal of Educational Sociology, 1936. Vol. IX, p. 515-523.

. Attitudes and the social act. Social problems, v. 3, n. 2, pp. 59-65, 1955. . Symbolic interactionism: Perspective and method. Englewood Cliffs, NJ: Prentice-Hall, 1969.

. A natureza do interacionismo simbólico. In: MORTESEN, David (Ed.). Teoria da Comunicação: textos básicos. São Paulo: Mosaico, 1980.

BonIn, Jiani Adriana. "Elementos para pensar a formação e o ensino em teorias da comunicação". In: MaldonAdo, Alberto Efendy. Conexão - Comunicação e Cultura, v. 4, n. 8, p. 61-68, 2005.

Certeau, Michel. A invenção do cotidiano: 1. Artes de fazer. Petrópolis, RJ: Vozes, 2004.

Foucault, Michel. História da loucura na Idade Clássica. São Paulo: Perspectiva, 1978.

Gakell, George. "Entrevistas individuais e grupais". In: Bauer, Martin W. \& Gakell, George. Pesquisa qualitativa com texto, imagem e som: um manual prático. Petrópolis: Vozes, 2002. pp. 64-89.

Goffman, Erving. Manicômios, prisões e conventos. São Paulo: Perspectiva, 1974/1961. . Asylums: Essays on the social situations of mental patients and other inmates. Nova York: Anchor, 1961.

MaldonAdo, Alberto Efendy et al. Metodologias de pesquisa em comunicação: olhares, trilhas e processos. Porto Alegre: Sulina, 2006.

Johnson, Telma. Nos bastidores da Wikipédia Lusófona: percalços e conquistas de um projeto de escrita colaborativa on-line. Rio de Janeiro: E-papers, 2010 (a).

. Pesquisa social mediada por computador: questões, metodologia e técnicas qualitativas. Rio de Janeiro: E-papers, 2010 (b).

MEAD, George. Mind, self, and society. Chicago: The University of Chicago Press, 1934.

Moretto, Vasco P. Planejamento: planejando a educação para o desenvolvimento de competências. Petrópolis: Vozes, 2012.

. Construtivismo: a produção do conhecimento em aula. Rio de Janeiro: Lamparina, 2011..

. Prova: um momento privilegiado de estudo, não um acerto de contas. Rio de Janeiro: Lamparina, 2010.NogueIRA, Luís. Manuais de cinema I: Laboratório de Guionismo. Covilhã: Livros LabCom, 2010. Disponível em: www.livroslabcom.ubi.pt. Acesso em: 30 de outubro de 2012.

$122 \frac{\text { Comunicação \& Inovação, PPGCOM/USCS }}{\text { v. 15, n. } 29 \text { (107-122) jul-dez } 2014}$ 